\title{
ES Cell Differentiation as a Model to Study Cell Biological Regulation of Vascular Development
}

\author{
Kiyomi Tsuji-Tamura, Hiroshi Sakamoto and Minetaro Ogawa \\ Institute of Molecular Embryology and Genetics, Kumamoto University \\ etpan
}

\section{Introduction}

The organized vascular system is established through three successive steps, vasculogenesis, angiogenesis and vascular remodeling. Vasculogenesis is the initiation of nascent embryonic vessel formation by the differentiation of mesoderm-derived angioblasts into endothelial cells. The nascent primitive vascular plexus then expands and reorganizes into hierarchical vascular structures by the process of angiogenesis, which involves sprouting, bridging, and intussusceptive division of preexisting vessels. Vascular smooth muscle cells are then recruited to the vessels and the highly organized mature vascular system is established after vascular remodeling. By using gene disruption strategies, a number of molecules have been identified as being involved in the development of the vascular system. These identified molecules include transcription factors, cell adhesion molecules, secretory molecules and their receptors, of which deprivation lead to failure of angiogenesis and/ or vascular remodeling in most cases. Despite the substantial expansion of the list of molecules that are essential for angiogenesis, we do not yet understand sufficiently how these molecules regulate the discrete processes of angiogenesis and vascular remodeling. Indeed, we know very little how normal endothelial cells behave in response to various angiogenic stimuli and cooperate to generate blood vessels during embryogenesis. It is critically important to establish an experimental model to study the functions of key molecules at the cellular level by monitoring the behavior of normal endothelial cells involving in angiogenesis.

In vitro differentiation systems of embryonic stem (ES) cells have been serving as an excellent experimental maneuver of developmental biology since Doetschman et al. reported that hematopoietic cells were generated in vitro from ES cells (Doetschman et al., 1985). The ES cell differentiation systems have three important features. First, as differentiation of cells and tissues takes place in a culture dish instead of uterus, the process of differentiation can be directly monitored. Second, intermediate stages of differentiation can be identified and isolated as a cell population. Third, cell differentiation and proliferation can be controlled by either adding exogenous signaling molecules, introducing exogenous genes or modifying endogenous genes. Following the pioneering report of angiogenic differentiation from mouse ES cells engrafted onto quail chorioallantoic membrane (Risau et al., 1988), in vitro derivation of vascular endothelial cells from ES cells has a history of almost two decades (Bloch et al., 1997; Feraud et al., 2001; Vittet et al., 1996; Wang et al., 1992). These earlier studies relied upon formation of cell aggregates termed cystic embryoid bodies from ES cells, whereby real-time monitoring of cell differentiation with a high resolution was 
hampered. Since Nishikawa's group developed a culture system in which ES cells differentiate into hematopoietic and endothelial cell lineages on type IV collagen-coated substrates or OP9 stromal cell layers (Hirashima et al., 1999; Yamashita et al., 2000), the simplicity of the culture system allowed detailed analysis of developmental steps essential in the formation of vascular and hematopoietic systems (Eilken et al., 2009; Kondo et al., 2009). This system thus provides a useful model to study cell biological regulation of endothelial cells in the process of angiogenesis and vascular remodeling. The aim of this chapter is to review our experimental models for the direct examination of differentiation, cell-cell adhesion, migration and morphological regulation of ES cell-derived endothelial cells, and discuss the cellular mechanisms underlying the process of vascular development.

\section{Endothelial cell-specific gene promoters and enhancers}

\subsection{Endothelial differentiation from murine ES cells}

It has been demonstrated that murine ES cells differentiate into Flk-1-expressing lateral mesodermal cells when cultured on a layer of OP9 stromal cell line (Endoh et al., 2002; Hashimoto et al., 2007; Kataoka et al., 1997; Nakano et al., 1994). In this culture system, undifferentiated ES cells are simply added to a culture flask pre-seeded with OP9 cells and incubated for 4 days in $\alpha$-MEM supplemented with 2-mercaptoethanol and fetal calf serum. Cultured cells are dissociated by incubating in a buffer containing chelating reagent, and stained with a monoclonal antibody against Flk-1. The cells expressing Flk-1, an equivalent population of proximal lateral mesoderm in the embryo (Kataoka et al., 1997), can be purified by fluorescence-activated cell sorting (FACS). When the purified Flk-1+ mesodermal cells are further cultured on a freshly prepared OP9 cell layer, they continue to differentiate into several cell lineages including primitive and definitive hematopoietic cells, cardiomyocytes, smooth muscle cells and endothelial cells. Vascular endothelial (VE)cadherin can be used as a specific marker to identify the endothelial cells. VE-cadherin+ (and also Flk-1+ CD31+) endothelial cells are finally isolated by FACS with specific monoclonal antibodies. Alternatively, when undifferentiated ES cells are allowed to differentiate on the OP9 cell layer for more than 5 days, endothelial cells can be isolated in a single step from the culture by FACS. In this case, Flk-1+ VE-cadherin- mesodermal cells become detectable on the 3rd day of differentiation, and Flk-1+ VE-cadherin ${ }^{+}$endothelial cells on the 5th day of differentiation (Endoh et al., 2002; Hashimoto et al., 2007). Consequently, this culture system is a potent and reproducible way to induce ES cell differentiation into the lateral mesoderm and its derivatives.

While the lineage-specific markers such as Flk-1 and VE-cadherin can be detected by using specific monoclonal antibodies thereby providing means to isolate desired cell populations, the induced expression of reporter genes under the control of lineage-specific gene promoter/ enhancer is another useful method especially for real-time monitoring of the process of cell differentiation. For example, Hirai et al. reported that a combination of 5' flanking region and 3' portion of the first intron of the $K d r$ (Flk-1) gene drove the expression of enhanced green fluorescent protein (EGFP) reporter gene shortly after generation of VEcadherin ${ }^{+}$endothelial cells during the differentiation of ES cell-derived Flk-1+ mesodermal cells (Hirai et al., 2003). As the $K d r$ promoter/ enhancer discriminates mature committed endothelial cells from immature endothelial cells that still possess a hematopoietic potential, it should be of use for monitoring the maturation process of endothelial cells. By contrast, a combination of 5' flanking region and 5' half of the first intron of the Cdh5 (VE-cadherin) 
gene was reported to be active exclusively in all of the VE-cadherin ${ }^{+}$endothelial cells during the course of ES cell differentiation, suggesting that the activity of the Cdh5 promoter/ enhancer reflects that of the endogenous Cdh5 gene (Hisatsune et al., 2005). Therefore, it provides a valuable tool for the endothelial cell-specific induction of a transgene expression regardless of differentiation stages. In the next section, we show another example of an endothelial-related enhancer element that might be useful to monitor endothelial cell differentiation from their precursor stages.

\subsection{Mef2c enhancer element and endothelial cell commitment}

De Val et al. reported that a 44bp element (F10-44) of an endothelial-specific transcriptional enhancer of the $M e f 2 c$ gene directed expression of lac $Z$ reporter specifically to the developing vascular endothelium of the mouse embryo (De Val et al., 2008). The element consists of a FOX:ETS motif that is present in many known endothelial-specific enhancers. The F10-44-lac $Z$ reporter mice demonstrated that this element was sufficient to direct endothelial cell-specific expression from the blood island stage at embryonic day (E) 7.5 through angiogenesis and remodeling at E9.5, and extinguished after E10.5 (De Val et al., 2008). The activity of F10-44 as early as E7.5, when the expression of VE-cadherin also becomes detectable (Breier et al., 1996; Nishikawa et al., 1998), prompted us to determine exactly when F10-44 is activated upon commitment of mesodermal cells to endothelial cells.

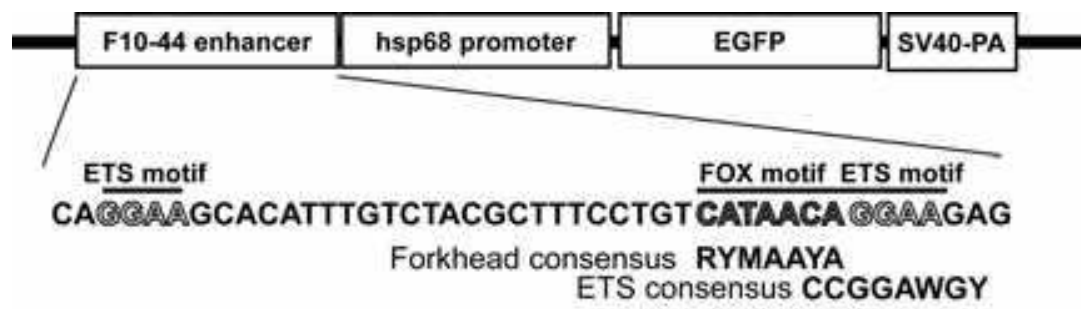

Fig. 1. Construction of F10-44-EGFP expression vector.

The EGFP reporter gene was connected to downstream of the F10-44 enhancer element and Hsp68 minimal promoter. Two ETS motifs and a FOX motif in the F10-44 element are indicated together with consensus sequences.

We transfected wild-type ES cells with a plasmid vector harboring EGFP reporter gene that is connected to downstream of F10-44 enhancer element and Hsp68 minimal promoter (Figure 1). ES cell clones were screened for proper controllability of EGFP expression by heat shock and sufficient capability of differentiating into endothelial cell lineage. We obtained three independent clones that showed essentially the same results. The F10-44-EGFP ES cells were cultured on OP9 stromal cell layer for 6 days to induce endothelial cell differentiation as described above. Flow cytometry analyses revealed that essentially all the VE-cadherin ${ }^{+}$ CD31+ endothelial cells activated the F10-44 enhancer as judged by expression of EGFP, indicating that the ES cell differentiation system recapitulated the activity of F10-44 in developing vascular endothelium of the mouse embryos (Figure 2). Expression of EGFP also distributed in the VE-cadherin- cell population, and the majority of them expressed Flk-1 yet. 

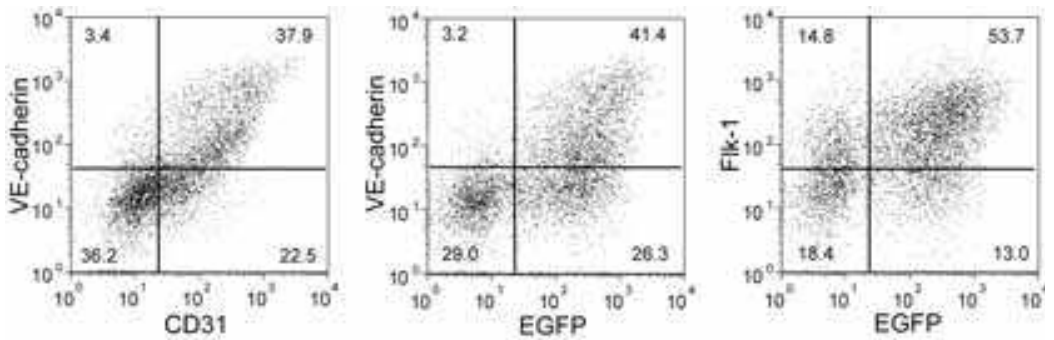

Fig. 2. Activity of F10-44 in ES cell-derived endothelial cells F10-44-EGFP ES cells were co-cultured with OP9 cells for 6 days. Differentiating cells were dissociated and analyzed for expression of endothelial cell markers and EGFP by flow cytometry. Numbers indicate the percentage of the cells in the quartered areas.

A
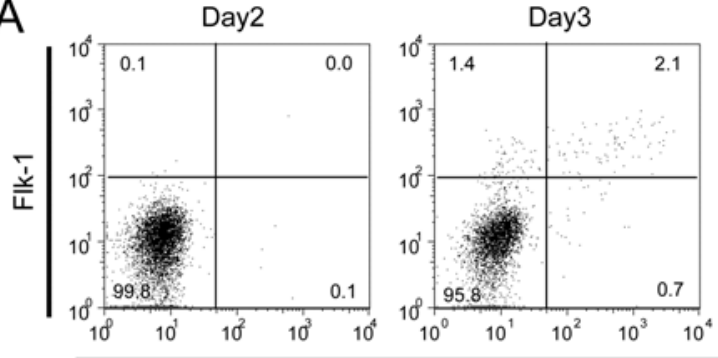

EGFP

B

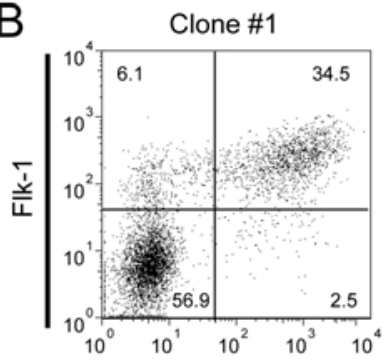

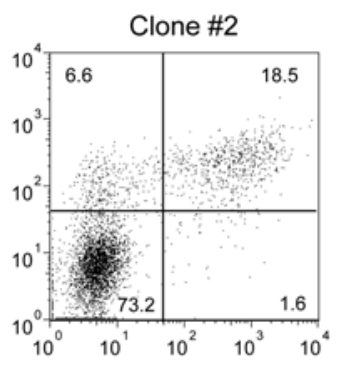

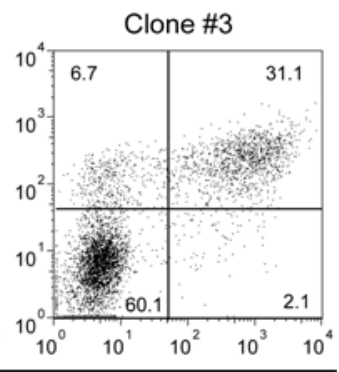

EGFP

Fig. 3. Activation of F10-44 in ES cell-derived mesodermal cells

(A) F10-44-EGFP ES cells were co-cultured with OP9 cells for 2-4 days. Differentiating cells were dissociated and analyzed for expression of Flk-1 and EGFP. (B) Three independent clones of F10-44-EGFP ES cells were co-cultured with OP9 cells for 4 days and analyzed in the same way as (A). Numbers indicate the percentage of the cells in the quartered areas.

In order to determine when the expression of EGFP begins during the course of ES cell differentiation, we examined the kinetics of mesodermal differentiation and EGFP expression. When F10-44-EGFP ES cells were allowed to differentiate on OP9 cell layer, an EGFP-expressing cell population emerged exclusively as a major subset of Flk-1+ mesodermal cells (Figure 3). As three independent ES clones showed the same pattern of 
EGFP expression, the activation of F10-44 in mesodermal cells is not a peculiar case of a selected clone, although we cannot exclude the possibility that it is specific to in vitro differentiation of ES cells.

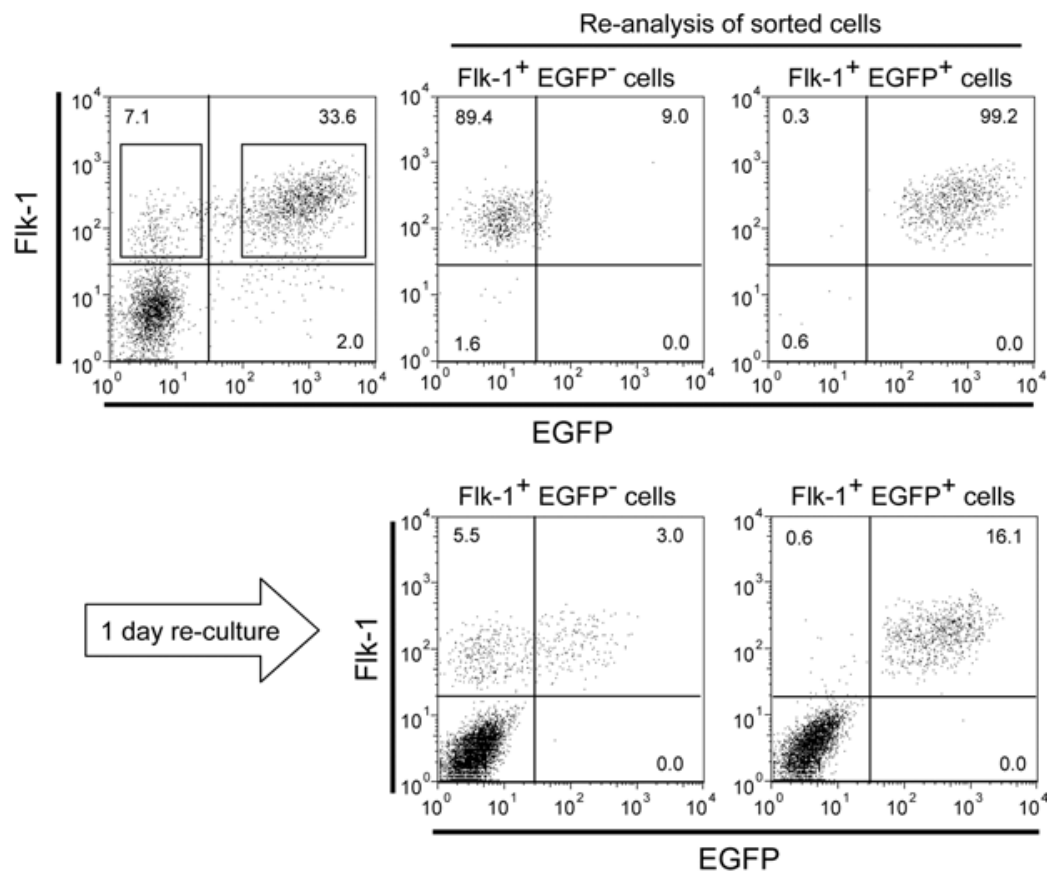

Fig. 4. Differentiation of Flk-1+ EGFP- cells to Flk-1+ EGFP+ cells

F10-44-EGFP ES cells were co-cultured with OP9 cells for 4 days. Flk-1+ EGFP- cells and Flk-

$1^{+} \mathrm{EGFP}^{+}$cells (indicated by the rectangles) were purified by FACS and re-cultured with OP9 cells. After 24 hours, cells were harvested and analyzed for expression of Flk-1 and EGFP. Numbers indicate the percentage of the cells in the quartered areas.

We next tested whether the Flk-1+ EGFP- cells differentiate to the Flk-1+ EGFP+ cells, and vice versa, by separating these cell populations with FACS and re-culturing them for 24 hours on a freshly prepared layer of OP9 cells. Figure 4 shows that the Flk-1+ EGFP- cells gave rise to the Flk-1+ EGFP+ cells within the culture period, while the Flk-1+ EGFP+ cells did not produce the Flk-1+ EGFP- cells. This observation suggests that the Flk-1+ EGFP- subset is more immature than the Flk-1+ $\mathrm{EGFP}^{+}$subset. With the aim of characterizing the two subsets of mesodermal cells in terms of multi-lineage differentiation capacity, we performed single cell sorting of these populations and examined for capabilities of each single cells to differentiate into endothelial cells, smooth muscle cells and cardiomyocytes, the three major derivatives of lateral mesoderm. Single cells were cultured separately on OP9 stromal cell layers for 7 days, followed by immunofluorescence staining of VE-cadherin (endothelial cells), desmin (smooth muscle cells) and troponin I (cardiomyocytes). Out of 48 single cells isolated from each of the Flk-1+ EGFP- and Flk-1+ EGFP+ cell subsets by FACS, thirty-six cells of each subsets showed the differentiation of at least one of the three cell lineages (Figure 5). 
Among of them, eighty percent of the Flk-1+ EGFP+ cells produced unipotential colonies containing only endothelial cells, although the rest of them retained a potential to differentiate into smooth muscle cells. By contrast, the Flk-1+ EGFP- cells produced a bipotential and a tripotential colony that contained cardiomyocytes, in addition to colonies containing endothelial cells and/ or smooth muscle cells. This observation supports the above assumption that the Flk-1+ EGFP- subset represents earlier differentiation stage of lateral mesoderm than the Flk-1+ EGFP+ subset.
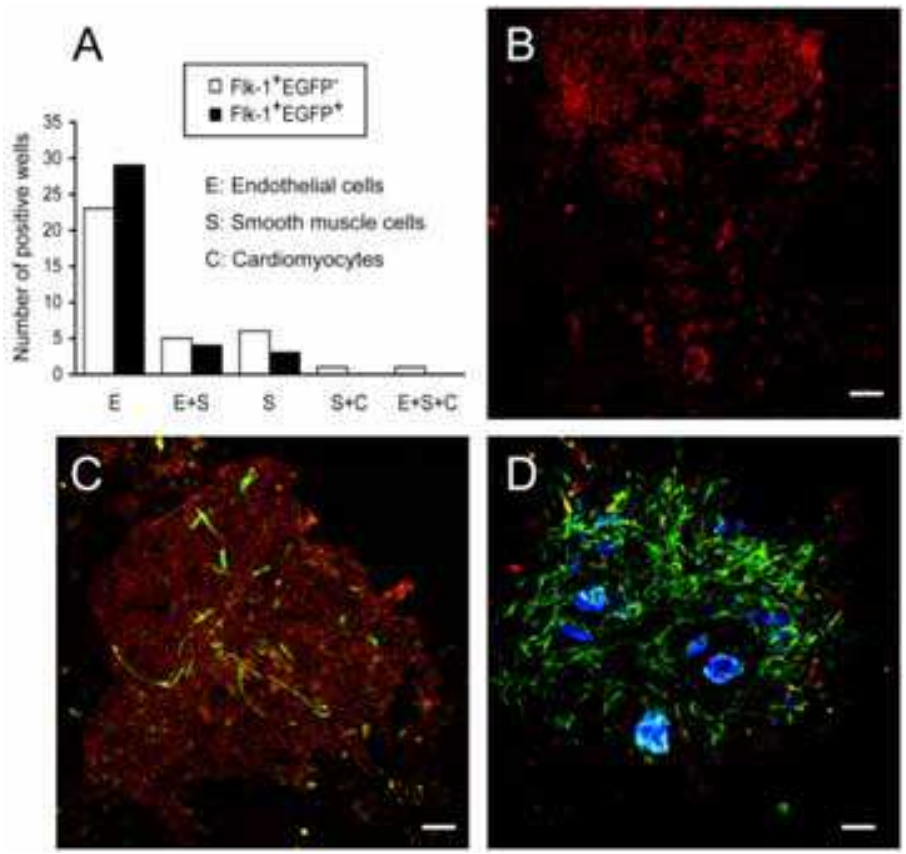

Fig. 5. Multi-lineage differentiation potential of mesodermal cells F10-44-EGFP ES cells were co-cultured with OP9 cells for 4 days. Forty-eight single cells of Flk-1+ EGFP- and Flk-1+ EGFP+ subsets were separately deposited into wells pre-seeded with OP9 cells. After 7 days cultivation, wells were stained with antibodies against VEcadherin (red), desmin (green) and troponin I (blue). (A) Number of wells that were positive for any of the three cell lineages. (B) A colony containing only endothelial cells. (C) A colony containing endothelial cells and smooth muscle cells. (D) A colony containing all the three cell lineages. Scale bars indicate $100 \mu \mathrm{m}$.

Our results suggest that the F10-44 enhancer element is first activated in a subset of lateral mesoderm, of which differentiation potential becomes restricted to the endothelial and smooth muscle cell lineages. As smooth muscle cells derived from Flk-1+ EGFP+ cells did not retain the expression of EGFP (data not shown), the F10-44 activity persists specifically in the endothelial cell lineage. It remains to be elucidated whether the early mesodermal activation of F10-44 also takes place in the mouse embryos, and whether the initiation of the F10-44 activity in the mesoderm and its maintenance in the endothelium are regulated by the same trans-activators. 


\subsection{Monitoring endothelial differentiation of mesodermal cells}

As mentioned above, F10-44 directed EGFP expression from endothelial precursors through differentiation of mature endothelial cells in ES cell cultures. Taking advantage of high visibility of EGFP fluorescence in living cells, the developmental process of endothelial precursors can be directly monitored by time-lapse analysis of differentiating ES cells. In order to detect the initiation of the F10-44 activity in mesodermal cells, we seeded F10-44EGFP ES cells onto OP9 stromal cell layer and performed time-lapse imaging analyses of differentiating cells.

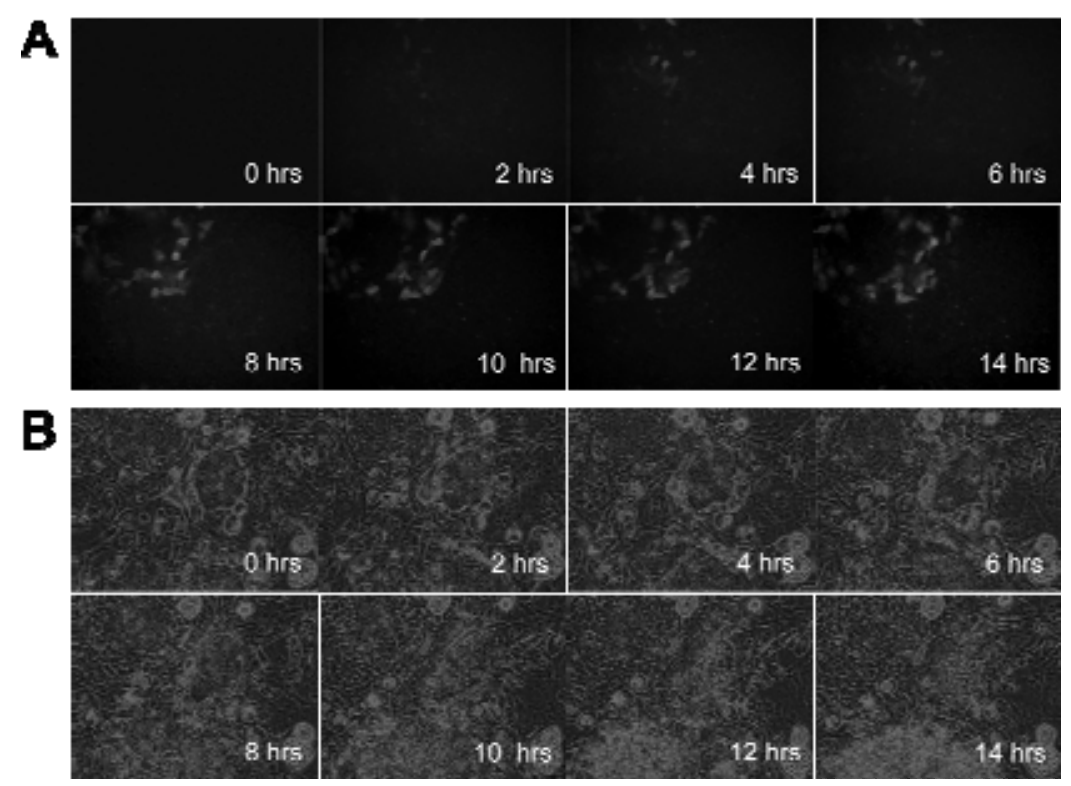

Fig. 6. Time-lapse analysis of differentiating mesodermal cells F10-44-EGFP ES cells were seeded on the OP9 cell layer to induce the mesodermal differentiation. After 3 days, the cultures were subjected to time-lapse analyses under a fluorescence microscope. Numbers indicate elapsed time counted by hours. (A) EGFP fluorescence images. (B) Phase contrast images.

As shown in Figure 6, progression of mesodermal cell differentiation as revealed by the emergence of EGFP fluorescence occurred within a group of cells in a relatively synchronous manner, rather than a clonal expansion of a single ancestral EGFP+ cells. This observation suggests that a group of mesodermal cells has determined their fate tow ard the endothelial cell lineage at a certain point, and then a combination of trans-activators activate F10-44 enhancer element synchronously in this population. The same sequence of events may also take place independently in other groups of mesoderm cells in culture. 


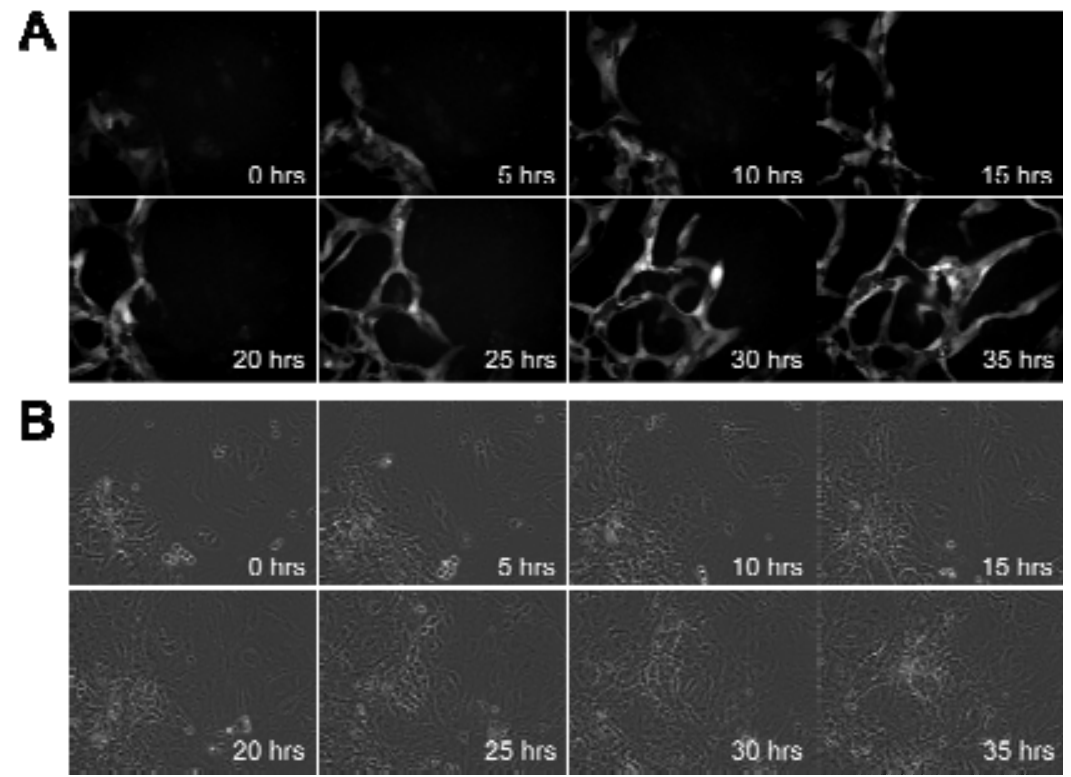

Fig. 7. Time-lapse analysis of differentiating endothelial cells

F10-44 EGFP ES cells were co-cultured with OP9 cells for 4 days, and Flk-1+ EGFP+ cells were purified by FACS. Cells were seeded on OP9 cell layer, and cultured in the presence of VEGF-A. After 36 hours, the cultures were subjected to time-lapse analyses under a fluorescence microscope. Numbers indicate elapsed time counted by hours. (A) EGFP fluorescence images. (B) Phase contrast images.

The F10-44 enhancer element also provides means of tracking how endothelial precursors are organized into endothelial structures in culture. F10-44-EGFP ES cells were co-cultured with OP9 stromal cells for 4 days. FACS-purified Flk-1+ EGFP+ cells were re-cultured on OP9 cell layer in the presence of $50 \mathrm{ng} / \mathrm{mL}$ vascular endothelial growth factor A (VEGF-A), and subjected to time-lapse analyses (Figure 7). The EGFP+ endothelial precursors first generated small groups of endothelial cells, and then the cells were rearranged to form large elongated clusters. Endothelial cells were further organized into a network of cord-like structures through splitting of elongated clusters, sprouting of endothelial cells with lamellipodial protrusions, migration and interconnection of elongated endothelial cells. These processes are reminiscent of those found in vasculogenesis and angiogenesis in the yolk sac vasculatures. Therefore, by combining the endothelial cell differentiation on OP9 stromal cell layer with the expression of fluorescent molecular probes, ES cell differentiation systems provide powerful experimental models to investigate the behavior of normal endothelial cells in response to angiogenic stimuli. We will discuss this point a little bit more in the next section.

\section{Cell-cell adhesion and motility of endothelial cells}

\subsection{Cell-cell junction as a regulating factor of endothelial cells}

Endothelial cells adhere to each other through tight junctions and adherens junctions. The tight junction regulates paracellular permeability and maintains cell polarity (Tsukita et al., 
2001). The tight junction is mediated by occludin, claudins and other transmembrane proteins associated with intracellular components such as ZO-1. The loss of claudin-5, a major adhesion molecule involved in the tight junction of endothelium, caused size-selective loosening of the blood-brain barrier (Nitta et al., 2003). Meanwhile, the adherens junction regulates the integrity of endothelium, paracellular permeability to solute, and transmigration of leukocytes across the endothelium (Bazzoni and Dejana, 2004). The adherens junction in endothelium is mediated by the homotypic binding of VE-cadherin and its anchorage to actin microfilaments through intracellular catenins. Disruption of the $C d h 5$ gene that encodes VE-cadherin resulted in impaired vascular remodeling and vessel collapse thereby led to embryonic lethality at E9.5 (Carmeliet et al., 1999; Gory-Faure et al., 1999).

Endothelial cells growing as sparse cells in culture are generally deemed to mimic the behavior of cells undergoing angiogenesis. They are stimulated to proliferate by growth factors and behave like fibroblasts, exhibiting elongated spindle-like shape and high motility. By contrast, confluent endothelial cells in culture are generally considered to be a model of resting endothelium. They develop organized adherens junctions and tight junctions, lose the ability to proliferate in response to growth factors, exhibit phenotypes of epithelioid cells, and remain static (Dejana, 2004). Indeed, in the absence of VE-cadherin, endothelial cells fail to display contact inhibition in culture and grow to higher density than cells expressing VE-cadherin (Grazia Lampugnani et al., 2003). Endothelial cells lacking VEcadherin also fail to respond to VEGF-A that protects them from apoptosis (Carmeliet et al., 1999). VE-cadherin and $\beta$-catenin form a complex with Flk-1/ VEGFR-2 and modulate its downstream signaling by influencing the phospholipase $\mathrm{C} \gamma$ and phosphatidylinositol 3kinase pathways, which regulates cell proliferation and survival, respectively. Therefore, the adherens junction appears to regulate not only the integrity of endothelium but also the proliferation and survival of endothelial cells. It is also reported that oligomerized angiopoietin-1 bridges Tie2 receptor at cell-cell contacts of confluent endothelial cells, resulting in formation of trans-association of Tie2 and activation of the Akt-Foxo1 and Aktendothelial NO synthase signaling pathways, which may enhance endothelial survival and integrity (Fukuhara et al., 2008).

Although many features of endothelial cells in the activated or resting state, especially cell proliferation and survival, are modeled by cultured endothelial cells, the supposed incompatibility between endothelial cell junctions and motility remains uncertain. Furthermore, it is also obscure whether the cell biological behaviors characterized by using cultures of mature endothelial cells such as human umbilical vein endothelial cells (HUVECs) are applicable to that of nascent endothelial cells involved in vascular development in the embryos. In this context, endothelial differentiation of ES cells may provide a means to investigate the behavior of nascent endothelial cells derived directly from progenitor cells.

\subsection{Endothelial cell movement compatible with junctional integrity}

We had developed a culture system in which endothelial cells derived from ES cells grow to form sheet-like colonies on a layer of OP9 stromal cells (Hirashima et al., 1999; Matsumura et $a l .$, 2003). In this culture system, differentiation of VE-cadherin ${ }^{+}$CD31+ endothelial cells is induced first from ES cells by co-cultivating with OP9 stromal cells. Endothelial cells are then purified by FACS and re-cultured on OP9 cell layers to allow colonies to form. In the 
absence of exogenous factors except for those secreted by OP9 cells or already contained in the serum, most of the colonies are round clusters of flat polygonal endothelial cells that are connected to each other via adherens junctions and tight junctions, which are revealed by VE-cadherin and claudin-5 immunostaining, respectively (Figure 8 and Guo et al., 2007).

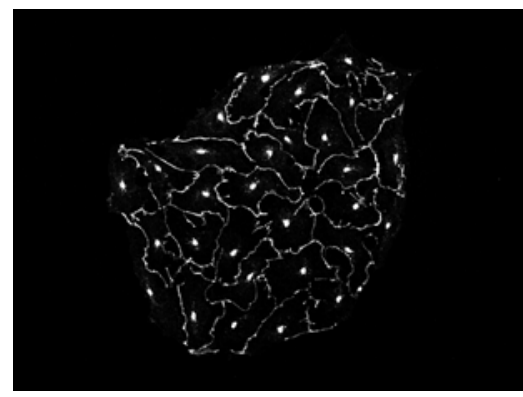

Fig. 8. Morphology of ES cell-derived endothelial cell colony

ES cells were co-cultured with OP9 cells for 5 days. VE-cadherin ${ }^{+}$CD31+ endothelial cells were purified by FACS, and seeded on OP9 cell layer. After 3 days, cultures were fluorescently stained with anti-VE-cadherin antibody to reveal endothelial cell colonies.

Interestingly, time-lapse analyses under a phase contrast microscope showed that endothelial cells moved continuously within the colonies. The average rate of cell movement was about $15 \mu \mathrm{m}$ per hour. Moving endothelial cells frequently displayed protrusive expansion of cell membrane in the direction of movement. To examine whether the endothelial cell movement involves active cell locomotion, we investigated subcellular dynamics of actin and Arp2/ 3 complex by using ES cell clones that constitutively express cytoplasmic $\beta$-actin or p41-Arc, a subunit of the Arp2/ 3 complex, both fused to EGFP. Timelapse analyses of EGFP- $\beta$-actin- or EGFP-p41Arc-expressing endothelial cell colonies under a fluorescence microscope revealed that the protrusive expansion of cell membrane was accompanied by dynamic accumulation of actin and Arp2/ 3 complex, which resembled the process of lamellipodium formation seen at the leading edge of a moving cell (Guo et al., 2007). These observations indicate an involvement of lamellipodium formation and active cell locomotion in the movement of endothelial cells within the colonies, even though the endothelial cells stay connected via adherens junctions and tight junctions.

In order to visualize the adherens junction and the tight junction on living endothelial cells, we established ES cell clones that express VE-cadherin or claudin-5, both tagged with Venus (a derivative of yellow fluorescent protein), under the control of the endothelial specific promoter/ enhancer of the Cdh5 (VE-cadherin) gene (Guo et al., 2007). When endothelial differentiation on the OP9 cell layer was induced from these ES cell clones, the VE-cadherinVenus or Venus-claudin-5 proteins were selectively localized at cell-cell boundaries of endothelial cell colonies. Time-lapse analyses of endothelial cell colonies under a fluorescence microscope demonstrated that moving endothelial cells changed shape continuously to maintain the integrity of adherens junctions and tight junctions (Figure 9 and Guo et al., 2007). Intercellular junctions underwent dynamic remodeling at the leading edge of moving endothelial cells, especially when a cell protrudes membrane and moves tow ard a lateral side of a contiguous cell. 


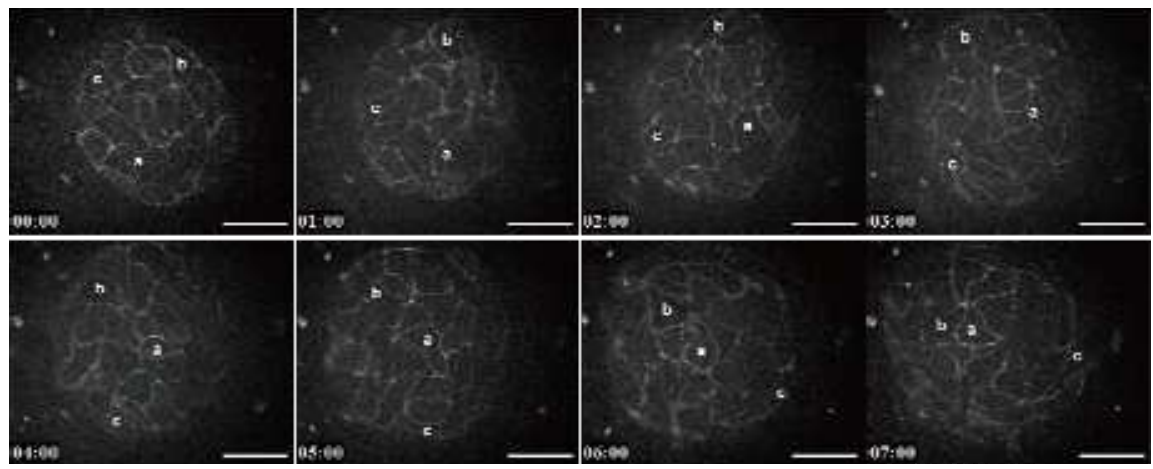

Fig. 9. Time-lapse imaging of adherens junctions on endothelial cells

An ES cell clone that express VE-cadherin-Venus under the control of endothelial-specific promoter/ enhancer of the $C d h 5$ gene was induced to differentiate into endothelial cells. FACS-purified endothelial cells were cultured on OP9 cell layer to form colonies. Colonies were subjected to time-lapse analysis under a fluorescence microscope to reveal dynamics of VE-cadherin-mediated adherens junctions. Numbers indicate elapsed time counted by hours. Three cells are individually labeled with alphabets to show the cell movement. Scale bars indicate $50 \mu \mathrm{m}$.

These results clearly indicate that the integrity of the adherens junction and the tight junction can be maintained as an endothelial cell migrates. It was reported that a monoclonal antibody against VE-cadherin disrupted adhesion of endothelial cells in growing vessels and prevented angiogenesis, suggesting that continuity of homotypic interaction of VE-cadherin is necessary for the process of angiogenesis (Corada et al., 2002). The compatibility of cell motility with junctional integrity should be an important characteristic of endothelial cells participating in angiogenesis. ES cell-derived endothelial cell colony formation serves as a useful model to study cell biological regulation of vascular development as further emphasized in the next section.

\section{Regulation of endothelial cell morphology during angiogenesis}

\subsection{Essential role of Foxo1 in vascular development}

Vascular development involves morphogenetic processes such as vasculogenesis, angiogenesis, and vascular remodeling. Mutant mouse models have implicated several key molecules in vascular development, including VEGF, platelet-derived growth factor, transforming growth factor- $\beta$ (TGF- $\beta$ ), angiopoietin, Notch, and ephrin/ Eph, the loss of which result in abnormal vascular development. However, little is known about how these molecules regulate the behavior of vascular components, indicating the importance of research at the cellular level that connects function of molecules and phenotype of mutant animals. A study on the regulation of angiogenesis by Foxo1 would be an example of such research.

Foxo 1 is a member of the Foxo subfamily of forkhead box transcription factors that promote cell cycle arrest, repair of damaged DNA, oxidative stress resistance, apoptosis and gluconeogenesis by regulating specific genes (van der Horst and Burgering, 2007). A role for Foxo1 in the developing vasculature was demonstrated by the observation that Foxo1(-/ -) 
mice die around E11 due to defects in the development of branchial arches and malformation in major vessels of the embryo and the yolk sac (Furuyama et al., 2004; Hosaka et al., 2004). Foxo1(-/ -) embryos developed a small first branchial arch, but no second branchial arch, and often exhibited marked pericardial swelling. The dorsal aorta was severely underdeveloped and irregularly formed. Hypoplasia of aortic arch artery was also observed. Foxo1(-/ -) yolk sacs showed primitive vascular plexus similar to that of wild-type yolk sacs at E8.75, but failed to develop a normal vasculature at E9.5. These observations suggested that vasculogenesis, but not angiogenesis and remodeling, proceeds without Foxo1. Expression of the Foxo1 gene was detected in developing vasculature of normal mouse embryos including the dorsal aorta, the intersomitic vessels, the vitelline and umbilical vessels and others (Furuyama et al., 2004; Hosaka et al., 2004). Although Foxo 1 has been considered as a key regulator of energy metabolism and lifespan, the role of this transcription factor in the vascular development can hardly be understood from the wellknown target genes. There was no significant difference between wild-type and Foxo1(-/ -) yolk sac in the expression levels of genes involved in vascular development including VEGF-A, VEGFR-1, VEGFR-2, angiopoietin-1, angiopoietin-2, Tie-1, Tie-2 and EphB4. Still, Foxo1(-/ -) yolk sac vasculature appeared to had lost an arterial property as indicated by reduced expression of arterial markers such as ephrinB2 and connexin-40 (Furuyama et al., 2004).

In order to delineate the role of Foxo 1 in angiogenesis, we employed an in vitro differentiation system of ES cells for investigating the expression and function of Foxo1 in endothelial cells. Foxo1 transcripts were detected in the VE-cadherin ${ }^{+} \mathrm{CD}^{+} 1^{+}$endothelial cells derived from wild-type ES cells differentiating in the co-culture with OP9 stromal cells (Furuyama et al., 2004). Comparable number of endothelial cells were able to be obtained from the cultures initiated from wild-type and Foxo1(-/ -) ES cells. Endothelial cells of the two genotypes also gave rise to comparable number and size of monostratal endothelial colonies when purified by FACS and re-seeded on the OP9 cell layer, suggesting that the loss of Foxo 1 did not influence the proliferation and survival of endothelial cells. This notion may contrast with a previous report that Foxo1 induced apoptosis in HUVECs, which was inhibited by angiopoietin-1 signaling via activation of Akt pathway (Daly et al., 2004). This discrepancy could reflect the difference in the differentiation stage of endothelial cells, namely, nascent immature endothelial cells derived from ES cells and mature endothelial cells isolated from established endothelium. The former may resemble the cells that undertake vascular development in the embryos.

We took advantage of the ES cell-derived endothelial cell colony formation assay to compare behavior of wild-type and Foxo1(-/ -) endothelial cells in response to various angiogenic stimuli. In the absence of exogenously added factors, endothelial cells of both genotypes formed monostratal colonies composed of rough-edged flat cells as described above. When VEGF-A was added in the medium during colony formation, however, wildtype and Foxo1(-/ -) endothelial cells exhibited quite different morphological responses. VEGF-A induced elongation of wild-type endothelial cells, thereby led to form colonies with corded structure composed of long spindle-shaped endothelial cells entwining with each other. In contrast to the response of wild-type endothelial cells, Foxo1(-/ -) endothelial cells remained flatten in the presence of exogenous VEGF-A. Yet they changed morphology from rough-edged to polygonal shape with rather straight adherens junctions and partially overlapped to the neighboring cells (Figure 10). (Endothelial cell overlapping as a stable condition is rarely observed in unstimulated monostratal colonies.) Induced expression of 
Foxo1 cDNA in the Foxo1(-/-) endothelial cells by using the endothelial-specific promoter/ enhancer of the $C d h 5$ (VE-cadherin) gene restored cell elongation in response to VEGF-A, implying a cell-autonomous function of Foxo1 in the morphological response of endothelial cells (Furuyama et al., 2004). Taken together, these results suggest that Foxo 1 regulates endothelial cell elongation in response to VEGF-A signaling, and the failure of proper morphological response of endothelial cells to angiogenic stimuli likely accounts for the compromised angiogenesis in the Foxo1(-/ -) embryos.
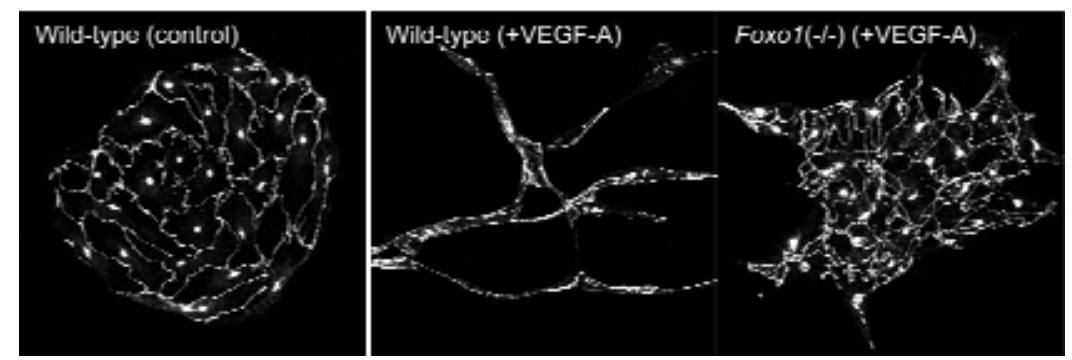

Fig. 10. Morphological response of endothelial cells to VEGF-A

Wild-type and Foxo1(-/ -) ES cells were co-cultured with OP9 cells for 5 days. VE-cadherin+ CD31+ endothelial cells were purified by FACS and seeded onto OP9 cell layer. Cells were cultured for 3 days in the presence or absence of exogenously added VEGF-A. Endothelial cell colonies were revealed by immunofluorescent staining of VE-cadherin.

\subsection{Endothelial cell elongation induced by angiogenic factors}

Severe dilation of the yolk sac blood vessels in Foxo1(-/ -) mice are reminiscent of mice lacking components of the TGF- $\beta$ signaling pathway including Alk5, Alk1, endoglin and Smad5 (Larsson et al., 2001; Li et al., 1999; Oh et al., 2000; Yang et al., 1999). It is well known that endothelial cells provide TGF- $\beta$ signaling to neighboring mesenchymal cells and promote their differentiation into smooth muscle cells which support and stabilize the vessels (ten Dijke and Arthur, 2007). However, endothelial cell-specific disruption of the Tgfbr2 or Alk5 gene resulted in the phenotype indistinguishable from that of the Tgfbr2-null or Alk5-null embryos, suggesting an endothelial cell-intrinsic role of TGF- $\beta$ signaling in the regulation of angiogenesis (Carvalho et al., 2004; Jiao et al., 2006). In order to examine whether Foxo 1 and TGF- $\beta$ are involved in a common process of angiogenesis, we tested the effect of TGF- $\beta$ on the morphology of ES cell-derived endothelial cells. VE-cadherin ${ }^{+}$CD31+ endothelial cells derived from wild-type and Foxo1(-/ -) ES cells differentiating in the coculture with OP9 cells were purified by FACS and re-seeded on the OP9 cell layer in the presence of TGF- $\beta$. Wild-type endothelial cells produced cord-like colonies composed of spindle-shaped cells in response to TGF- $\beta$. By contrast, Foxo1(-/ -) endothelial cells failed to produce cord-like colonies, but they exhibited partial overlapping as in the case of VEGF-A treatment (Matsukawa et al., 2009). These observations indicate that TGF- $\beta$ induces elongation of endothelial cells in a Foxo1-dependent manner.

Sequestration of a low concentration of endogenous VEGF-A pre-existing in the culture (mainly secreted by OP9 cells) by addition of Flt1-Fc chimeric protein diminished TGF- $\beta$ induced elongation of wild-type endothelial cells, indicating that endothelial cell elongation induced by TGF- $\beta$ depends upon VEGF-A signaling (Matsukawa et al., 2009). As the amount 
of Vegfa transcripts in OP9 cells was not influenced by the stimulation with TGF- $\beta$, two possible mechanisms might be implied. First, TGF- $\beta$ may synergize with VEGF-A to regulate endothelial cell morphology, and Foxo1 is possibly involved in the TGF- $\beta$ signaling. It is indeed reported that Foxo proteins interacted with Smad3 and Smad4 to form a p21Cip1 transactivation complex in the regulation of neuroepithelial and glioblastoma cell proliferation by TGF- $\beta$ (Seoane et al., 2004). Alternatively, TGF- $\beta$ may reduce the threshold of VEGF-A-responsiveness of endothelial cells, thereby facilitates cell elongation under the presence of a limited amount of VEGF-A, which is dependent upon Foxo1. Nevertheless, the observations that TGF- $\beta$ induced endothelial cell elongation in a Foxo1-dependent manner and that disruption of Foxo1 and TGF- $\beta$ signaling resulted in a similar phenotype in vascular development suggest important roles of Foxo1-dependent endothelial cell elongation in the process of angiogenesis.

\subsection{Distinct functions of Foxo subfamily members}

The Foxo subfamily of forkhead box transcription factors consists of four members (Foxo1, Foxo3, Foxo4 and Foxo6). Somatic deletion of the Foxo1, Foxo3 and Foxo4 genes in adult mice revealed that Foxo 1 is the major regulator of endothelial stability which suppresses endothelial growth and hemangioma development, yet a certain degree of functional redundancy appears to exist among the Foxo members (Paik et al., 2007). Indeed, both Foxo 1 and Foxo3 were reported to induce apoptosis in HUVECs (Daly et al., 2004; Kim et al., 2005). Foxo1 and Foxo3, but not Foxo4, were also shown to comparably inhibit endothelial cell migration and tube formation in vitro (Potente et al., 2005). However, Foxo 1 appears to have nonredundant functions in vascular development during embryogenesis. In contrast to the defect of angiogenesis in Foxo1(-/ -) embryos, both Foxo3(-/ -) and Foxo4(-/ -) mice are born alive with no detectable abnormality of vascular development (Castrillon et al., 2003; Hosaka et al., 2004). Dispensability of these two genes for vascular development possibly due to differential tissue distribution of the Foxo members in developing embryos, since the expression of Foxo1, Foxo3 and Foxo4 mRNA in the embryos were complementary to each other (Furuyama et al., 2000). Alternatively, molecular functions of the Foxo members in the endothelium are possibly diversified. For instance, expression of several genes that are related to inflammation and angiogenesis (e.g. angiopoietin-2 and interleukin-8) are differentially regulated by Foxo1 and Foxo3 in HUVECs (Potente et al., 2005).

We examined expression of Foxo3 during the course of ES cell differentiation into endothelial cell lineage. While Foxo1 was expressed constantly by undifferentiated ES cells, Flk-1+ mesodermal cells and various stages of VE-cadherin ${ }^{+} \mathrm{CD}^{+} 1^{+}$endothelial cells, expression of Foxo3 was not detected in any of these cell populations (Matsukawa et al., 2009). Therefore, Foxo 1 appears to be a primary and nonredundant factor that regulates morphological response of developing endothelial cells to angiogenic stimulations. In order to gain insight into the molecular mechanisms underlying the cell morphological regulation by Foxo1, we investigated whether or not Foxo3 is able to functionally replace Foxo 1 when expressed as a transgene in Foxo1(-/ -) endothelial cells (Matsukawa et al., 2009). We recruited a tetracycline-regulated gene expression system to induce the expression of either Foxo1 or Foxo3 protein in Foxo1(-/ -) endothelial cells. In this system, a tetracycline responsive promoter drives expression of either the Foxo1 or Foxo3 transgene when activated by a tetracycline transactivator in the absence of tetracycline, or suppresses it in the presence of tetracycline. The expression system was introduced into Foxo1(-/ -) ES cells, and tightly 
controllable clones were selected. The Foxo1- or Foxo3-inducible Foxo1(-/ -) ES cell clones were allowed to differentiate into endothelial cells by co-culturing with OP9 stromal cells for 5 days in the presence of tetracycline (to suppress the transgene expression), followed by FACS purification of endothelial cells. The sorted endothelial cells were seeded onto OP9 cell layer in the presence of VEGF-A, and the transgene was activated by withdrawal of tetracycline. Morphological examination of endothelial cell colonies revealed that induction of Foxo 1 in Foxo1(-/ -) endothelial cells led to cell elongation that is almost comparable to wild-type endothelial cells. In contrast to the effect of Foxo1, induction of Foxo3 in Foxo1(-/ ) endothelial cells failed to restore the VEGF-A-dependent elongation, suggesting that Foxo3 is not able to exert the same function as does Foxo1 in promoting endothelial cell elongation in response to VEGF-A signaling (Matsukaw a et al., 2009).

ES cell-derived endothelial cell cultures represent ongoing processes of endothelial cell differentiation such as the upregulation of CD34 and Flt1 expression and activation of the promoter/ enhancer element of the Flk-1 gene (Hirai et al., 2003; Hirashima et al., 1999; Hirashima et al., 2003). Interestingly, when endothelial cells were isolated from 6 days culture of differentiating Foxo3-inducible ES cell clones (i.e. 24 hours later than the abovedescribed experiments) and examined for morphological response to VEGF-A, induction of Foxo3 restored the VEGF-A-dependent endothelial cell elongation (Matsukaw a et al., 2009). It is thus suggested that endothelial cells serially activate two different mechanisms of morphological regulation during the differentiation process. Foxo1 is involved in both mechanisms, while Foxo3 is able to participate only in the late-acting mechanism. Taken together, we hypothesize that distinct functions as well as distribution of Foxo 1 and Foxo3 in endothelial cells may account for the difference of the phenotypes between Foxo1(-/ -) and Foxo3(-/ -) embryos.

The functional disparity of Foxo members in endothelial cells should provide valuable clue to clarify the molecular mechanisms underlying the regulation of endothelial cell morphology by Foxo1. Identification of Foxo1 target genes that are responsible for the morphological regulation is of critical importance. We performed DNA microarray analysis to compare gene expression profiles of the endothelial cells derived from wild-type and Foxo1(-/ -) ES cells by using the 3D-Gene Mouse Oligo chip 24 (Toray Industries Inc.). Among a total of 25,392 genes, we identified 207 genes that were differentially expressed in the wild-type and Foxo1(-/ -) endothelial cells. From the 207 genes, we further excluded genes of which expression was influenced in the same direction (increased or decreased) by the induction of Foxo1 or Foxo3 in Foxo1(-/ -) endothelial cells. Thirty-one genes were finally selected as candidate genes, and in vitro functional screening is currently underway. Once a target gene of Foxo 1 that is responsible for the regulation of endothelial cell morphology is identified, expression of the candidate gene should be genetically manipulated in the Foxo1(/ -) embryos to examine whether or not it restores the abnormal angiogenesis caused by Foxo1-deficiency, which will finally testify to the importance of Foxo1-dependent morphological regulation of endothelial cells in vascular development.

\subsection{Vessel-like structure formation from ES cells}

In order to understand the role of Foxo 1 in the regulation of endothelial cell morphology, it is important to investigate how the cytoskeletal organization of endothelial cells is influenced in the absence of functional Foxo1. However, the OP9 cell-dependent twodimensional culture described in the preceding sections is not suitable for microscopic 
observation of cytoskeletal structures of endothelial cells due to interference of the robust cytoskeleton of OP9 cells. In addition, endothelial cell behavior is induced not only by exogenously added factors but might also be influenced by unknown molecules secreted by OP9 cells. It is thus necessary to establish an experimental model in which endothelial cell behavior can be examined in the absence of stromal cells. Yamashita et al. previously reported that ES cell-derived Flk-1+ mesodermal cells produced vessel-like structures consisting of endothelial tubes supported by smooth muscle cells in a type I collagen gel culture with VEGF-A (Yamashita et al., 2000). This three-dimensional culture system is able to circumvent the need of OP9 feeder cells and provide an in vitro model for studying the morphological change of endothelia cells into a capillary-like structure and its association with smooth muscle cells. We employed and further improved the culture system to investigate the impact of Foxo1-deficiency on the cytoskeletal organization of endothelial cells and the formation of vessel-like structures (Park et al., 2009).

In the culture system, ES cells were cultured with OP9 cells for 4 days to induce differentiation of Flk-1+ mesodermal cells. Flk-1+ cells were purified by FACS and allowed to aggregate in suspension culture. Flk-1+ cell aggregates were embedded in type I collagen gel and cultured for 4 days in the presence of VEGF-A to form vessel-like structures. Domelike collagen gels were finally flattened by liquid absorption for fixation and immunostaining. Gel flattening greatly facilitated immunofluorescence staining and confocal microscopic observation of the vessel-like structures deeply embedded in the gels (Park et al., 2009). Wild-type endothelial cells showed spindle-shaped elongation as revealed by rectilinear staining of VE-cadherin along the long axis of the cells, and organized into long cord-like structures. On the other hand, Foxo1(-/ -) endothelial cells failed to elongate and produced only short bundles with irregularly kinked adherens junctions, demonstrating that Foxo 1 is essential for elongation of endothelial cells that are organized into vessel-like structures in vitro (Figure 11, 12 and Park et al., 2009).

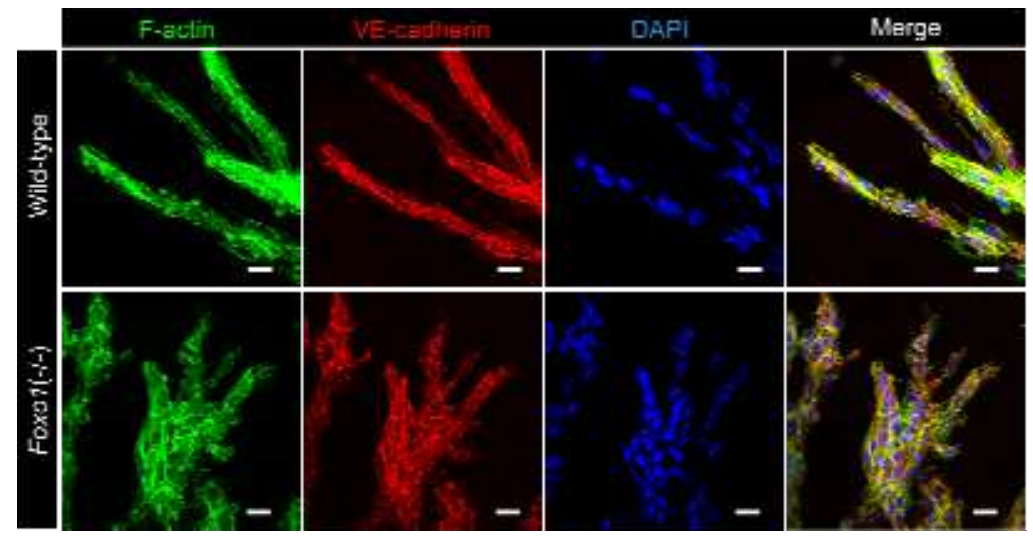

Fig. 11. Abnormal vessel-like structure formation from Foxo1(-/ -) mesodermal cells Wild-type and Foxo1(-/ -) ES cells were co-cultured with OP9 cells for 4 days. FACS-purified mesodermal cells were cultured in type I collagen gel in the presence of VEGF-A for 4 days. Vessel-like structures were fluorescently stained with phalloidin, anti-VE-cadherin antibody and DAPI. Scale bars indicate $10 \mu \mathrm{m}$. 


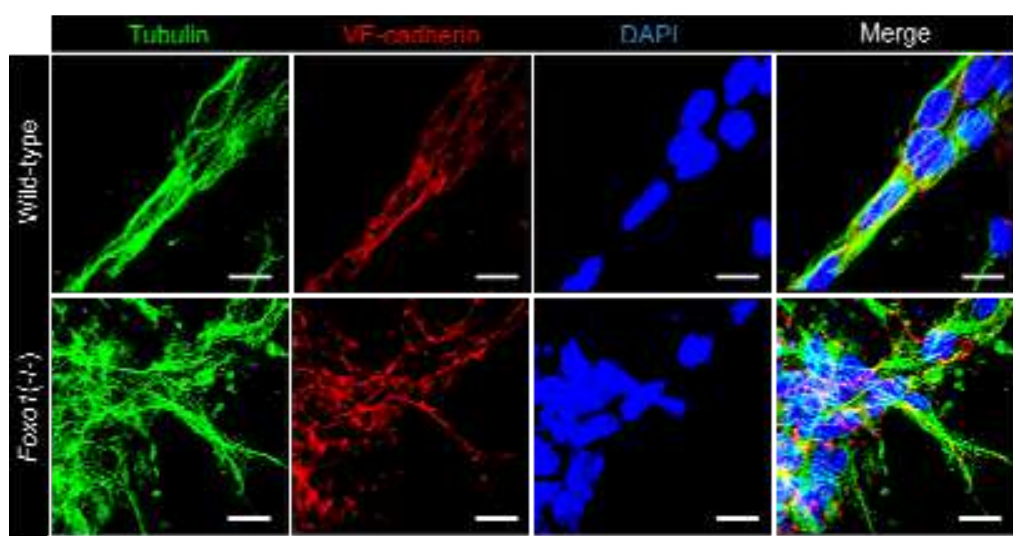

Fig. 12. Microtubular organization of endothelial cells in the vessel-like structures

Wild-type and Foxo1(-/ -) ES cells were co-cultured with OP9 cells for 4 days. FACS-purified mesodermal cells were cultured in type I collagen gel in the presence of VEGF-A for 4 days. Vessel-like structures were fluorescently stained with antibodies against tubulin and VEcadherin together with DAPI. Scale bars indicate $10 \mu \mathrm{m}$.

Phalloidin staining revealed that prominent filamentous cortical actin which co-localized with VE-cadherin at the adherens junction was present in wild-type endothelial cells. By contrast, F-actin was not only accumulated to the adherens junctions but also scattered as punctate structures in Foxo1(-/ -) endothelial cells. The punctate accumulation of F-actin is unlikely to represent the focal adhesion complex, because only vinculin, but not paxillin nor focal adhesion kinase, was co-localized with the punctate structures. Indeed, the stress fiber formation was not observed in both wild-type and Foxo1(-/ -) endothelial cells (Park et al., 2009). These results suggested that Foxo1-deficiency led to abnormal organization of actin cytoskeleton, which might influence the adhesion and migration of endothelial cells.

Cell elongation requires the reorganization of microtubules as well as actin cytoskeleton. While long filamentous microtubules in a mesh-like network were observed in wild-type endothelial cells, Foxo1(-/ -) endothelial cells developed thick circumferential accumulation of microtubules with small spikes at the tip of cells (Park et al., 2009). It is thus suggested that Foxo1-deficiency leads to disorganization of microtubular system in endothelial cells, which may resemble a condition resulted from hyper stabilization of microtubules (Gloushankova et al., 1994). It was proposed that cell length is controlled by the equilibrium of two antagonistic forces: elongation exerted by integrated microtubular system and contraction exerted by actinmyosin system (Kharitonova and Vasiliev, 2008). We hypothesize that hyper stabilization of microtubules as well as circumferential accumulation of actin microfilaments may contribute to the failure of elongation of Foxo1(-/ -) endothelial cells.

Pharmacological approaches by using chemicals that influence the cytoskeletal organization would be useful to investigate the molecular basis of impaired elongation of Foxo1(-/ -) endothelial cells. One of the advantages of the three-dimensional culture system is that it circumvents the need of OP9 stromal cell layer, which might otherwise be affected by such chemicals and secondarily influence the morphology of endothelial cells. Taking advantage of the culture system, we tested effects of Y27632, a compound that inhibits Rho kinase (ROCK), on the formation of vessel-like structures (Figure 13 and 14). 


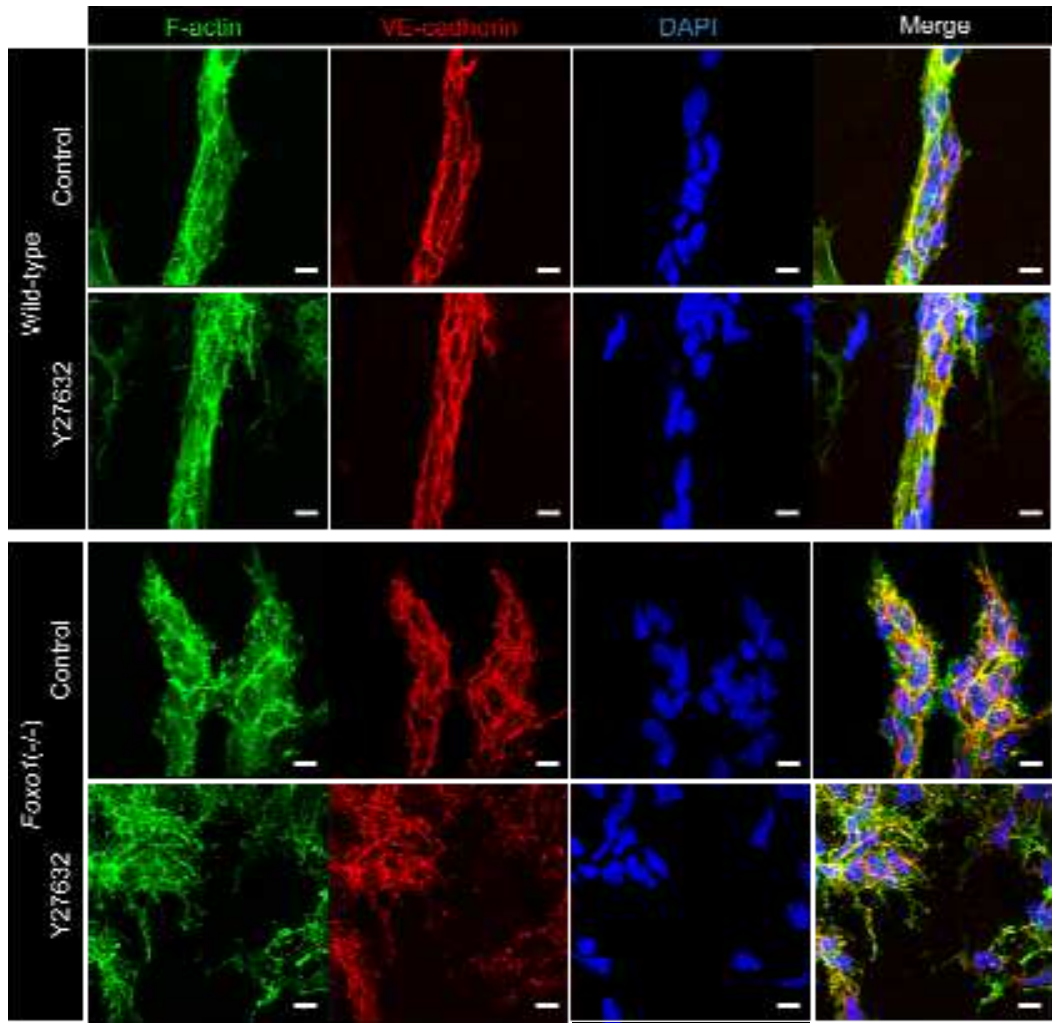

Fig. 13. Aberrant dependency on RhoA/ ROCK pathw ay in Foxo1(-/ -) endothelial cells Wild-type and Foxo1(-/ -) ES cells were co-cultured with OP9 cells for 4 days. FACS-purified mesodermal cells were cultured in type I collagen gel in the presence of VEGF-A and presence or absence of Y27632. Vessel-like structures were fluorescently stained with phalloidin, anti-VE-cadherin antibody and DAPI. Scale bars indicate $10 \mu \mathrm{m}$.

Flk-1+ cells isolated from differentiating wild-type or Foxo1(-/ -) ES cells were allowed to aggregate and embedded in type I collagen gel and cultured in the presence of $50 \mathrm{ng} / \mathrm{mL}$ VEGF-A and presence or absence of $10 \mu \mathrm{M}$ Y27632. VE-cadherin immunofluorescence staining of flattened gels revealed that wild-type Flk-1+ cells generated capillary-like structures consisting of spindle-shaped endothelial cells regardless of whether Y27632 was present or absent in the culture. Actin microfilaments and microtubule networks were not also affected by Y27632 treatment. These observations indicate that ROCK inhibition does not affect the elongation of wild-type endothelial cells and the formation of capillary-like structures in vitro. By contrast, treatment with Y27632 resulted in extreme disintegration of cell organization in the cultures of Foxo1(-/ -) endothelial cells. Adherens junctions revealed by VE-cadherin and F-actin staining became fragmentary and distributed in a disorderly manner. Microtubules also exhibited short fluffiness with random distribution. Consequently, Foxo1(-/ -) endothelial cells no longer maintained even short bundles in the presence of Y27632. Foxo1(-/ -) endothelial cells thus appear to be abnormally dependent on the RhoA/ ROCK pathway. 


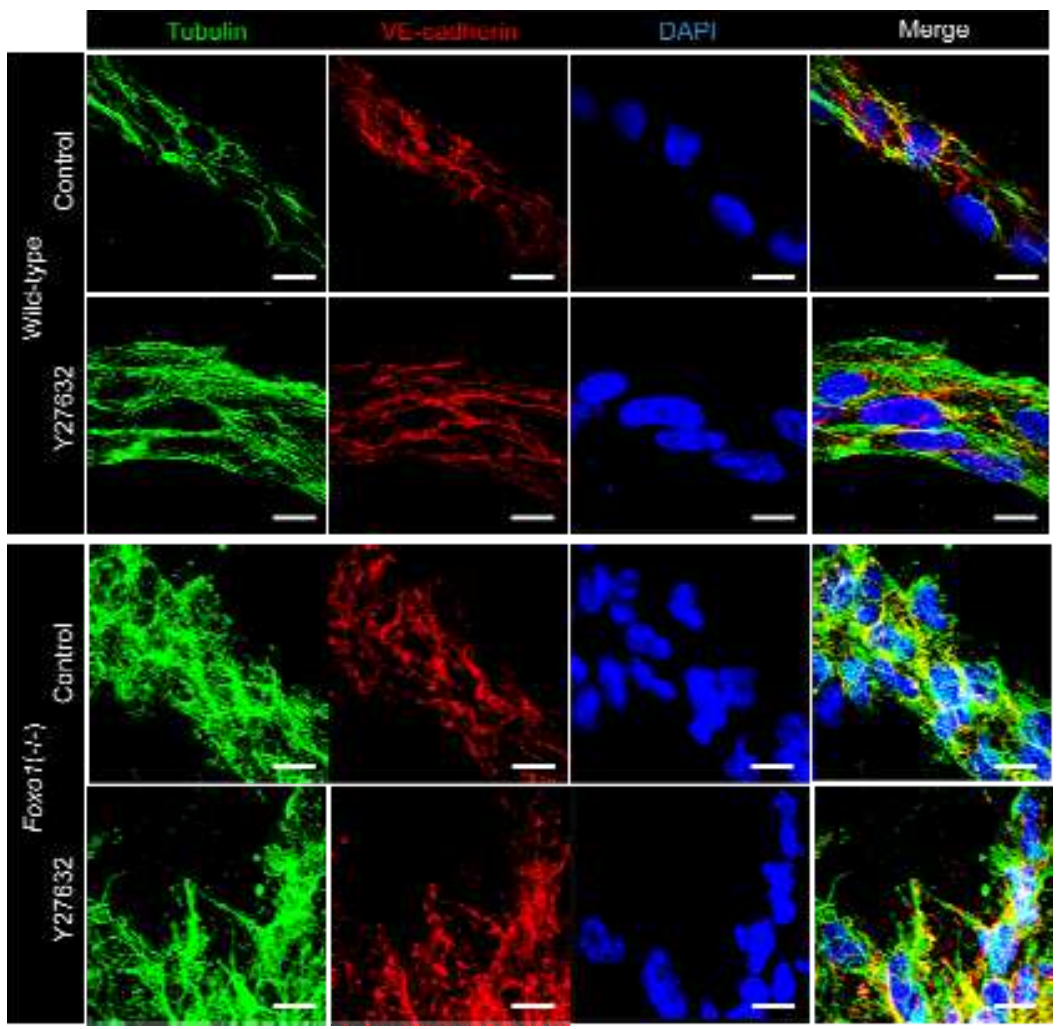

Fig. 14. Microtubular organization of ROCK-inhibited endothelial cells Wild-type and Foxo1(-/ -) ES cells were co-cultured with OP9 cells for 4 days. FACS-purified mesodermal cells were cultured in type I collagen gel in the presence of VEGF-A and presence or absence of Y27632. Vessel-like structures were fluorescently stained with

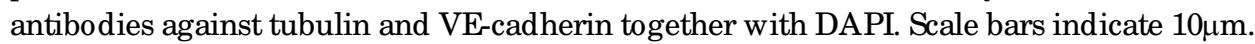

Our results suggest that the RhoA/ ROCK pathway is not involved in the regulation of endothelial cell morphology or there might be some compensatory pathways in the wildtype genetic background. On the other hand, Foxo1(-/ -) endothelial cells are suggested to harbor an abnormal enhancement of the RhoA/ ROCK pathway or lack the putative compensatory pathways. However, the enhancement of ROCK-dependency itself might be the effect, rather than the cause, of abnormal morphological response of Foxo1(-/ -) endothelial cells to VEGF-A, because the inhibition of ROCK activity did not restore the abnormal phenotype. Nevertheless, the aberrant requirement of the RhoA/ ROCK pathway for the maintenance of cell organization provides clue to how a loss of Foxo 1 compromises cytoskeletal organization and morphological response of endothelial cells during angiogenesis. 


\subsection{Association between endothelial cells and smooth muscle cells}

Correct association and interaction between endothelial cells and smooth muscle cells is known to be essential for vascular maturation. The capillary-like structure generated in vitro from ES cell-derived Flk-1+ mesodermal cells consists of endothelial tubes associated with mural cells that express $\alpha$-smooth muscle actin ( $\alpha$ SMA). A massive investment of mural cells is usually observed along the vascular-like structures. Endothelial cells and mural cells exhibit patchy formation of desmosome-like junctions and some collagen fibers are evident adjacent to the mural cells, indicating that these cells interact with each other to form mature vessel-like structures in vitro (Yamashita et al., 2000).

Interestingly, while the capillary-like structures generated from wild-type mesodermal cell aggregates were thoroughly covered by $\alpha \mathrm{SMA}^{+}$mural cells, no such coverage of $\alpha \mathrm{SMA}^{+}$ cells was observed along the short endothelial cell bundles generated from Foxo1(-/ -) mesodermal cell aggregates (Figure 15 and Park et al., 2009). Yet, $\alpha \mathrm{SMA}+$ cells were abundantly detected in the core region of Foxo1(-/ -) cell aggregates and occasionally apart from cell aggregates, and Foxo1(-/ -) $\alpha$ SMA + cells are morphologically indistinguishable from wild-type $\alpha \mathrm{SMA}+$ cells (Figure 16). Therefore, differentiation of smooth muscle cells from Flk-1+ cells was not affected by the absence of Foxo1. These results suggest that Foxo1 is essential for either the migration of mural cells or the physical interaction between mural cells and endothelial cells, although it is obscure whether functional Foxo1 is required autonomously in mural cells or heteronomously in endothelial cells.

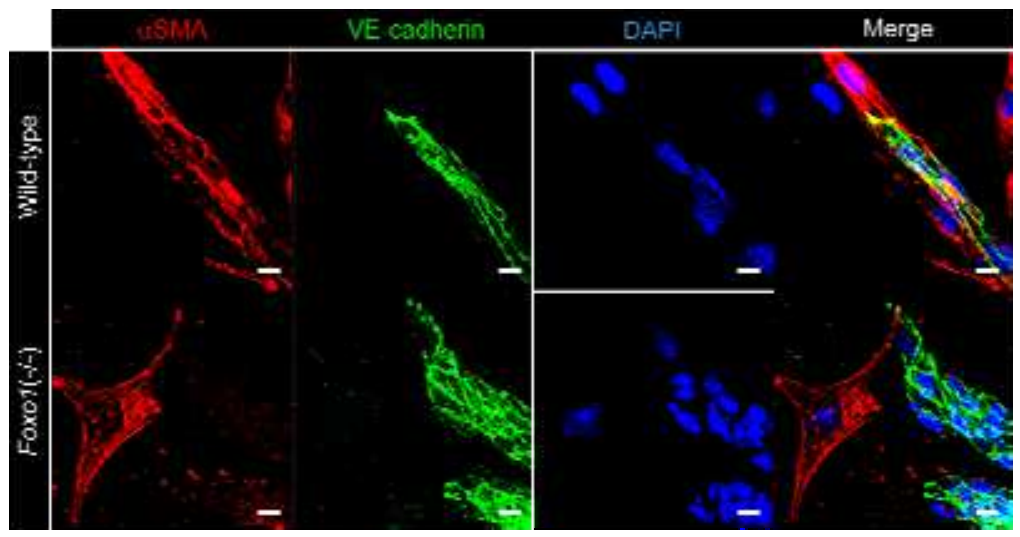

Fig. 15. Impaired association of mural cells with endothelial cells in Foxo1(-/ -) cultures Wild-type and Foxo1(-/ -) ES cells were co-cultured with OP9 cells for 4 days. FACS-purified mesodermal cells were cultured in type I collagen gel in the presence of VEGF-A for 4 days. Vessel-like structures were fluorescently stained with antibodies against $\alpha$ SMA and VEcadherin together with DAPI. Scale bars indicate $10 \mu \mathrm{m}$. 
We hypothesize from the above observations that Foxo 1 is involved in the recruitment of mural cells to nascent blood vessels. However, it has not been documented whether or not the interaction of endothelial cells and mural cells is maintained in the blood vessels of Foxo1(-/ -) embryos (Furuyama et al., 2004; Hosaka et al., 2004). Thus, further phenotypic characterization of the knockout embryos is clearly important. The yolk sac vasculature of Foxo1(-/ -) embryos had dilated and lost the arterial identity as mentioned above. This might be an indicative of a loss of supportive force exerted by mural cells to maintain the hemodynamic property that is necessary to induce arterial differentiation (Heil et al., 2006). The functional necessity of Foxo1 in vascular smooth muscle cells in the embryo is an important subject for future studies.

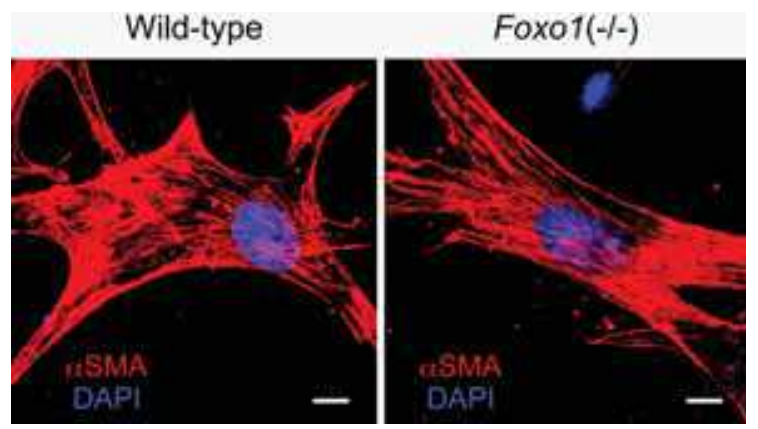

Fig. 16. Morphology of ES cell-derived smooth muscle cells

Wild-type and Foxo1(-/ -) ES cells were co-cultured with OP9 cells for 4 days. FACS-purified mesodermal cells were cultured in type I collagen gel in the presence of VEGF-A. Smooth muscle cells were revealed by immunofluorescent staining with anti- $\alpha$ SMA antibody. Scale bars indicate $10 \mu \mathrm{m}$.

\section{Conclusion}

Differentiation, migration, cell-cell adhesion and morphological regulation of vascular endothelial cells are the important cell biological processes that drive vasculogenesis and angiogenesis. In vitro differentiation of ES cells provides useful means to elucidate the mechanisms underlying cell biological regulation of vascular development. Further improvement will, however, be necessary for simplification of the system to raise the controllability of cell biological processes. Such an improvement should encompass the replacement of the OP9 stromal cell layer with a defined extracellular matrix with variable elasticity. Establishing the cell biology of normal endothelial cells and understanding the cell biological control of vascular development will contribute to not only developmental biology but also clinical approaches for regulation of physiological and pathological neoangiogenesis in ischemic tissues and tumors.

\section{Acknowledgements}

We wish to thank the members, past and present, of the Department of Cell Differentiation, Institute of Molecular Embryology and Genetics, Kumamoto University. This work was 
supported by grants from the Ministry of Education, Culture, Sports, Sciences and Technology (MEXT) of Japan and Japan Society for the Promotion of Science. This work was supported in part by Global COE Program (Cell Fate Regulation Research and Education Unit), MEXT, Japan.

\section{References}

Bazzoni, G. \& Dejana, E. (2004). Endothelial cell-to-cell junctions: molecular organization and role in vascular homeostasis. Physiol Rev, Vol. 84, No. 3, 869-901.

Bloch, W., Forsberg, E., Lentini, S., Brakebusch, C., Martin, K., Krell, H.W., Weidle, U.H., Addicks, K. \& Fassler, R. (1997). Beta 1 integrin is essential for teratoma growth and angiogenesis. JCell Biol, Vol. 139, No. 1, 265-278.

Breier, G., Breviario, F., Caveda, L., Berthier, R., Schnurch, H., Gotsch, U., Vestweber, D., Risau, W. \& Dejana, E. (1996). Molecular cloning and expression of murine vascular endothelial-cadherin in early stage development of cardiovascular system. Blood, Vol. 87, No. 2, 630-641.

Carmeliet, P., Lampugnani, M.G., Moons, L., Breviario, F., Compernolle, V., Bono, F., Balconi, G., Spagnuolo, R., Oostuyse, B., Dewerchin, M., et al. (1999). Targeted deficiency or cytosolic truncation of the VE-cadherin gene in mice impairs VEGFmediated endothelial survival and angiogenesis. Cell, Vol. 98, No. 2, 147-157.

Carvalho, R.L., Jonker, L., Goumans, M.J., Larsson, J., Bouwman, P., Karlsson, S., Dijke, P.T., Arthur, H.M. \& Mummery, C.L. (2004). Defective paracrine signalling by TGFbeta in yolk sac vasculature of endoglin mutant mice: a paradigm for hereditary haemorrhagic telangiectasia. Development, Vol. 131, No. 24, 6237-6247.

Castrillon, D.H., Miao, L., Kollipara, R., Horner, J.W. \& DePinho, R.A. (2003). Suppression of ovarian follicle activation in mice by the transcription factor Foxo3a. Science, Vol. 301, No. 5630, 215-218.

Corada, M., Zanetta, L., Orsenigo, F., Breviario, F., Lampugnani, M.G., Bernasconi, S., Liao, F., Hicklin, D.J., Bohlen, P. \& Dejana, E. (2002). A monoclonal antibody to vascular endothelial-cadherin inhibits tumor angiogenesis without side effects on endothelial permeability. Blood, Vol. 100, No. 3, 905-911.

Daly, C., Wong, V., Burova, E., Wei, Y., Zabski, S., Griffiths, J., Lai, K.M., Lin, H.C., Ioffe, E., Yancopoulos, G.D., et al. (2004). Angiopoietin-1 modulates endothelial cell function and gene expression via the transcription factor FKHR (FOXO1). Genes Dev, Vol. 18, No. 9, 1060-1071.

De Val, S., Chi, N.C., Meadows, S.M., Minovitsky, S., Anderson, J.P., Harris, I.S., Ehlers, M.L., Agarwal, P., Visel, A., Xu, S.M., et al. (2008). Combinatorial regulation of endothelial gene expression by ets and forkhead transcription factors. Cell, Vol. 135, No. 6, 1053-1064.

Dejana, E. (2004). Endothelial cell-cell junctions: happy together. Nat Rev Mol Cell Biol, Vol. 5, No. 4, 261-270.

Doetschman, T.C., Eistetter, H., Katz, M., Schmidt, W. \& Kemler, R. (1985). The in vitro development of blastocyst-derived embryonic stem cell lines: formation of visceral yolk sac, blood islands and myocardium. I Embryol. Exp. Morphol., Vol. 87, 27-45. 
Eilken, H.M., Nishikawa, S. \& Schroeder, T. (2009). Continuous single-cell imaging of blood generation from haemogenic endothelium. Nature, Vol. 457, No. 7231, 896900 .

Endoh, M., Ogawa, M., Orkin, S. \& Nishikawa, S. (2002). SCL/ tal-1-dependent process determines a competence to select the definitive hematopoietic lineage prior to endothelial differentiation. Embo J, Vol. 21, No. 24, 6700-6708.

Feraud, O., Cao, Y. \& Vittet, D. (2001). Embryonic stem cell-derived embryoid bodies development in collagen gels recapitulates sprouting angiogenesis. Lab Invest, Vol. 81, No. 12, 1669-1681.

Fukuhara, S., Sako, K., Minami, T., Noda, K., Kim, H.Z., Kodama, T., Shibuya, M., Takakura, N., Koh, G.Y. \& Mochizuki, N. (2008). Differential function of Tie2 at cell-cell contacts and cell-substratum contacts regulated by angiopoietin-1. Nat Cell Biol, Vol. 10, No. 5, 513-526.

Furuyama, T., Kitayama, K., Shimoda, Y., Ogawa, M., Sone, K., Yoshida-Araki, K., Hisatsune, H., Nishikawa, S., Nakayama, K., Nakayama, K., et al. (2004). Abnormal angiogenesis in Foxo1 (Fkhr)-deficient mice. JBiol Chem, Vol. 279, No. 33, 3474134749 .

Furuyama, T., Nakazawa, T., Nakano, I. \& Mori, N. (2000). Identification of the differential distribution patterns of mRNAs and consensus binding sequences for mouse DAF16 homologues. Biochem J, Vol. 349, No. Pt 2, 629-634.

Gloushankova, N.A., Lyubimova, A.V., Tint, I.S., Feder, H.H., Vasiliev, J.M. \& Gelfand, I.M. (1994). Role of the microtubular system in morphological organization of normal and oncogene-transfected epithelial cells. Proc Natl Acad Sci U S A, Vol. 91, No. 18, 8597-8601.

Gory-Faure, S., Prandini, M.H., Pointu, H., Roullot, V., Pignot-Paintrand, I., Vernet, M. \& Huber, P. (1999). Role of vascular endothelial-cadherin in vascular morphogenesis. Development, Vol. 126, No. 10, 2093-2102.

Grazia Lampugnani, M., Zanetti, A., Corada, M., Takahashi, T., Balconi, G., Breviario, F., Orsenigo, F., Cattelino, A., Kemler, R., Daniel, T.O., et al. (2003). Contact inhibition of VEGF-induced proliferation requires vascular endothelial cadherin, beta-catenin, and the phosphatase DEP-1/ CD148. JCell Biol, Vol. 161, No. 4, 793-804.

Guo, R., Sakamoto, H., Sugiura, S. \& Ogawa, M. (2007). Endothelial cell motility is compatible with junctional integrity. JCell Physiol, Vol. 211, No. 2, 327-335.

Hashimoto, K., Fujimoto, T., Shimoda, Y., Huang, X., Sakamoto, H. \& Ogawa, M. (2007). Distinct hemogenic potential of endothelial cells and CD41(+) cells in mouse embryos. Dev Growth Differ, Vol. 49, No. 4, 287-300.

Heil, M., Eitenmuller, I., Schmitz-Rixen, T. \& Schaper, W. (2006). Arteriogenesis versus angiogenesis: similarities and differences. eburnal of cellular and molecular medicine, Vol. 10, No. 1, 45-55.

Hirai, H., Ogawa, M., Suzuki, N., Yamamoto, M., Breier, G., Mazda, O., Imanishi, J. \& Nishikawa, S. (2003). Hemogenic and nonhemogenic endothelium can be distinguished by the activity of fetal liver kinase (Flk)-1 promoter/ enhancer during mouse embryogenesis. Blood, Vol. 101, No. 3, 886-893. 
Hirashima, M., Kataoka, H., Nishikawa, S., Matsuyoshi, N. \& Nishikawa, S. (1999). Maturation of embryonic stem cells into endothelial cells in an in vitro model of vasculogenesis. Blood, Vol. 93, No. 4, 1253-1263.

Hirashima, M., Ogawa, M., Nishikawa, S., Matsumura, K., Kawasaki, K., Shibuya, M. \& Nishikawa, S. (2003). A chemically defined culture of VEGFR2+ cells derived from embryonic stem cells reveals the role of VEGFR1 in tuning the threshold for VEGF in developing endothelial cells. Blood, Vol. 101, No. 6, 2261-2267.

Hisatsune, H., Matsumura, K., Ogawa, M., Uemura, A., Kondo, N., Yamashita, J.K., Katsuta, H., Nishikawa, S. \& Chiba, T. (2005). High level of endothelial cell-specific gene expression by a combination of the 5 ' flanking region and the 5 ' half of the first intron of the VE-cadherin gene. Blood, Vol. 105, No. 12, 4657-4663.

Hosaka, T., Biggs, W.H., 3rd, Tieu, D., Boyer, A.D., Varki, N.M., Cavenee, W.K. \& Arden, K.C. (2004). Disruption of forkhead transcription factor (FOXO) family members in mice reveals their functional diversification. Proc Natl Acad Sci U S A, Vol. 101, No. 9, 2975-2980.

Jiao, K., Langw orthy, M., Batts, L., Brown, C.B., Moses, H.L. \& Baldwin, H.S. (2006). Tgfbeta signaling is required for atrioventricular cushion mesenchyme remodeling during in vivo cardiac development. Development, Vol. 133, No. 22, 4585-4593.

Kataoka, H., Takakura, N., Nishikawa, S., Tsuchida, K., Kodama, H., Kunisada, T., Risau, W., Kita, T. \& Nishikawa, S.I. (1997). Expressions of PDGF receptor alpha, c-Kit and Flk1 genes clustering in mouse chromosome 5 define distinct subsets of nascent mesodermal cells. Dev. Growth. Differ., Vol. 39, No. 6, 729-740.

Kharitonova, M.A. \& Vasiliev, J.M. (2008). Controlling cell length. Seminars in cell \& developmental biology, Vol. 19, No. 6, 480-484.

Kim, H.S., Skurk, C., Maatz, H., Shiojima, I., Ivashchenko, Y., Yoon, S.W., Park, Y.B. \& Walsh, K. (2005). Akt/ FOXO3a signaling modulates the endothelial stress response through regulation of heat shock protein 70 expression. Faseb $J$, Vol. 19, No. 8, 10421044.

Kondo, N., Ogawa, M., Wada, H. \& Nishikawa, S. (2009). Thrombin induces rapid disassembly of claudin-5 from the tight junction of endothelial cells. Exp Cell Res, Vol. 315, No. 17, 2879-2887.

Larsson, J., Goumans, M.J., Sjostrand, L.J., van Rooijen, M.A., Ward, D., Leveen, P., Xu, X., ten Dijke, P., Mummery, C.L. \& Karlsson, S. (2001). Abnormal angiogenesis but intact hematopoietic potential in TGF-beta type I receptor-deficient mice. Embo $J$, Vol. 20, No. 7, 1663-1673.

Li, D.Y., Sorensen, L.K., Brooke, B.S., Urness, L.D., Davis, E.C., Taylor, D.G., Boak, B.B. \& Wendel, D.P. (1999). Defective angiogenesis in mice lacking endoglin. Science, Vol. 284, No. 5419, 1534-1537.

Matsukawa, M., Sakamoto, H., Kawasuji, M., Furuyama, T. \& Ogawa, M. (2009). Different roles of Foxo 1 and Foxo3 in the control of endothelial cell morphology. Genes Cells, Vol. 14, No. 10, 1167-1181.

Matsumura, K., Hirashima, M., Ogawa, M., Kubo, H., Hisatsune, H., Kondo, N., Nishikawa, S., Chiba, T. \& Nishikawa, S. (2003). Modulation of VEGFR-2-mediated endothelialcell activity by VEGF-C/ VEGFR-3. Blood, Vol. 101, No. 4, 1367-1374. 
Nakano, T., Kodama, H. \& Honjo, T. (1994). Generation of lymphohematopoietic cells from embryonic stem cells in culture. Science, Vol. 265, No. 5175, 1098-1101.

Nishikawa, S.I., Nishikawa, S., Kawamoto, H., Yoshida, H., Kizumoto, M., Kataoka, H. \& Katsura, Y. (1998). In vitro generation of lymphohematopoietic cells from endothelial cells purified from murine embryos. Immunity, Vol. 8, 761-769.

Nitta, T., Hata, M., Gotoh, S., Seo, Y., Sasaki, H., Hashimoto, N., Furuse, M. \& Tsukita, S. (2003). Size-selective loosening of the blood-brain barrier in claudin-5-deficient mice. JCell Biol, Vol. 161, No. 3, 653-660.

Oh, S.P., Seki, T., Goss, K.A., Imamura, T., Yi, Y., Donahoe, P.K., Li, L., Miyazono, K., ten Dijke, P., Kim, S., et al. (2000). Activin receptor-like kinase 1 modulates transforming growth factor-beta 1 signaling in the regulation of angiogenesis. Proc Natl Acad Sci U S A, Vol. 97, No. 6, 2626-2631.

Paik, J.H., Kollipara, R., Chu, G., Ji, H., Xiao, Y., Ding, Z., Miao, L., Tothova, Z., Horner, J.W., Carrasco, D.R., et al. (2007). FoxOs are lineage-restricted redundant tumor suppressors and regulate endothelial cell homeostasis. Cell, Vol. 128, No. 2, 309-323.

Park, S.H., Sakamoto, H., Tsuji-Tamura, K., Furuyama, T. \& Ogawa, M. (2009). Foxo1 is essential for in vitro vascular formation from embryonic stem cells. Biochem Biophys Res Commun, Vol. 390, No. 3, 861-866.

Potente, M., Urbich, C., Sasaki, K., Hofmann, W.K., Heeschen, C., Aicher, A., Kollipara, R., DePinho, R.A., Zeiher, A.M. \& Dimmeler, S. (2005). Involvement of Foxo transcription factors in angiogenesis and postnatal neovascularization. JClin Invest, Vol. 115, No. 9, 2382-2392.

Risau, W., Sariola, H., Zerwes, H.G., Sasse, J., Ekblom, P., Kemler, R. \& Doetschman, T. (1988). Vasculogenesis and angiogenesis in embryonic-stem-cell-derived embryoid bodies. Development, Vol. 102, No. 3, 471-478.

Seoane, J., Le, H.V., Shen, L., Anderson, S.A. \& Massague, J. (2004). Integration of Smad and forkhead pathways in the control of neuroepithelial and glioblastoma cell proliferation. Cell, Vol. 117, No. 2, 211-223.

ten Dijke, P. \& Arthur, H.M. (2007). Extracellular control of TGFbeta signalling in vascular development and disease. Nat Rev Mol Cell Biol, Vol. 8, No. 11, 857-869.

Tsukita, S., Furuse, M. \& Itoh, M. (2001). Multifunctional strands in tight junctions. Nat Rev Mol Cell Biol, Vol. 2, No. 4, 285-293.

van der Horst, A. \& Burgering, B.M. (2007). Stressing the role of FoxO proteins in lifespan and disease. Nat Rev Mol Cell Biol, Vol. 8, No. 6, 440-450.

Vittet, D., Prandini, M.H., Berthier, R., Schweitzer, A., Martin Sisteron, H., Uzan, G. \& Dejana, E. (1996). Embryonic stem cells differentiate in vitro to endothelial cells through successive maturation steps. Blood, Vol. 88, No. 9, 3424-3431.

Wang, R., Clark, R. \& Bautch, V.L. (1992). Embryonic stem cell-derived cystic embryoid bodies form vascular channels: an in vitro model of blood vessel development. Development, Vol. 114, No. 2, 303-316.

Yamashita, J., Itoh, H., Hirashima, M., Ogawa, M., Nishikawa, S., Yurugi, T., Naito, M., Nakao, K. \& Nishikawa, S. (2000). Flk1-positive cells derived from embryonic stem cells serve as vascular progenitors. Nature, Vol. 408, No. 6808, 92-96. 
Yang, X., Castilla, L.H., Xu, X., Li, C., Gotay, J., Weinstein, M., Liu, P.P. \& Deng, C.X. (1999). Angiogenesis defects and mesenchymal apoptosis in mice lacking SMAD5. Development, Vol. 126, No. 8, 1571-1580. 


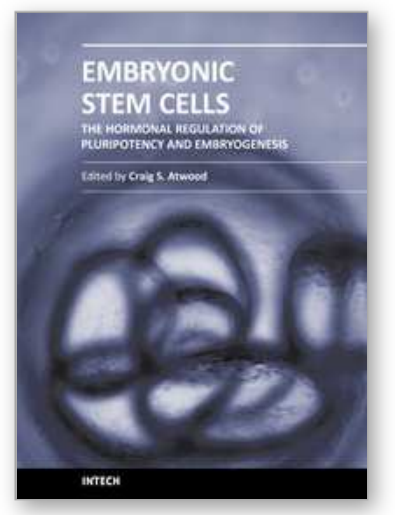

\section{Embryonic Stem Cells: The Hormonal Regulation of Pluripotency and Embryogenesis}

Edited by Prof. Craig Atwood

ISBN 978-953-307-196-1

Hard cover, 672 pages

Publisher InTech

Published online 26, April, 2011

Published in print edition April, 2011

Pluripotency is a prerequisite for the subsequent coordinated differentiation of embryonic stem cells into all tissues of the body. This book describes recent advances in our understanding of pluripotency and the hormonal regulation of embryonic stem cell differentiation into tissue types derived from the ectoderm, mesoderm and endoderm.

\section{How to reference}

In order to correctly reference this scholarly work, feel free to copy and paste the following:

Kiyomi Tsuji-Tamura, Hiroshi Sakamoto and Minetaro Ogawa (2011). ES Cell Differentiation as a Model to Study Cell Biological Regulation of Vascular Development, Embryonic Stem Cells: The Hormonal Regulation of Pluripotency and Embryogenesis, Prof. Craig Atwood (Ed.), ISBN: 978-953-307-196-1, InTech, Available from: http://www.intechopen.com/books/embryonic-stem-cells-the-hormonal-regulation-of-pluripotency-andembryogenesis/es-cell-differentiation-as-a-model-to-study-cell-biological-regulation-of-vascular-development

\section{INTECH}

open science | open minds

\author{
InTech Europe \\ University Campus STeP Ri \\ Slavka Krautzeka 83/A \\ 51000 Rijeka, Croatia \\ Phone: +385 (51) 770447 \\ Fax: +385 (51) 686166 \\ www.intechopen.com
}

\author{
InTech China \\ Unit 405, Office Block, Hotel Equatorial Shanghai \\ No.65, Yan An Road (West), Shanghai, 200040, China \\ 中国上海市延安西路65号上海国际贵都大饭店办公楼 405 单元 \\ Phone: +86-21-62489820 \\ Fax: $+86-21-62489821$
}


(C) 2011 The Author(s). Licensee IntechOpen. This chapter is distributed under the terms of the Creative Commons Attribution-NonCommercialShareAlike-3.0 License, which permits use, distribution and reproduction for non-commercial purposes, provided the original is properly cited and derivative works building on this content are distributed under the same license. 